\title{
Luis Eduardo Wuffarden \& Ricardo Kusunoki. Plata en los Andes
}

Lima: Banco de Crédito del Perú y Museo de Arte de Lima, 2018, 351

pages, ilustrations

Pedro M. Guibovich Pérez

\section{(2) OpenEdition}

Journals

Edición electrónica

URL: http://journals.openedition.org/bifea/9917

DOI: $10.4000 /$ bifea.9917

ISSN: 2076-5827

Editor

Institut Français d'Études Andines

Edición impresa

Fecha de publicación: 1 agosto 2018

Paginación: 217-219

ISSN: 0303-7495

Referencia electrónica

Pedro M. Guibovich Pérez, « Luis Eduardo Wuffarden \& Ricardo Kusunoki. Plata en los Andes », Bulletin de l'Institut français d'études andines [En línea], 47 (2) | 2018, Publicado el 08 agosto 2018, consultado el 05 noviembre 2020. URL : http://journals.openedition.org/bifea/9917 ; DOI : https://doi.org/10.4000/ bifea.9917

Este documento fue generado automáticamente el 5 noviembre 2020.

\section{c)}

Les contenus du Bulletin de l'Institut français d'études andines sont mis à disposition selon les termes de la licence Creative Commons Attribution - Pas d'Utilisation Commerciale - Pas de Modification 4.0 International. 


\title{
Luis Eduardo Wuffarden \& Ricardo Kusunoki. Plata en los Andes
}

\author{
Lima: Banco de Crédito del Perú y Museo de Arte de Lima, 2018, 351 \\ pages, ilustrations
}

Pedro M. Guibovich Pérez

\section{REFERENCIA}

Luis Eduardo Wuffarden \& Ricardo Kusunoki. Plata en los Andes. Lima: Banco de Crédito del Perú y Museo de Arte de Lima, 2018, 351 pages, ilustrations

1 La plata ha sido objeto de codicia en todos los tiempos. Los conquistadores españoles que llegaron a los Andes a inicios del siglo XVI no fueron la excepción, como tampoco los oficiales de la Corona y otros miembros de la sociedad colonial. Mas la plata trabajada, convertida en objeto, es para los historiadores una valiosísima fuente documental para auscultar los modos de vida, las expectativas y creencias, las prácticas sociales, los gustos estéticos, entre muchos otros aspectos del pasado y del presente. Por eso debemos celebrar la publicación del libro Plata de los Andes, editado por Luis Eduardo Wuffarden y Ricardo Kusunoki, porque sin duda está llamado a convertirse en una esencial obra de referencia para el estudio de la orfebrería colonial y republicana.

2 El libro consta de tres partes. La primera ofrece tres ensayos a cargo de Luis Eduardo Wuffarden, Carmen Heredia Moreno y Emily Floyd, respectivamente. En «Los plateros: notas sobre la evolución de un oficio artístico», Wuffarden traza un acucioso panorama general acerca de los artesanos durante la conquista española de los Andes, los primeros indígenas que desempeñaron el oficio, las ordenanzas dadas por el virrey Francisco Toledo para reglamentar el oficio de platero, la cofradía de San Eloy. Pero acaso el aporte más interesante de su ensayo tiene que ver con la evolución estética de la platería desde el siglo XVI hasta la segunda mitad del siglo XIX. Wuffarden ilustra dicha evolución a partir de fuentes primarias y secundarias así como de los mismos objetos, resultado de los gustos de sus propietarios como de las modas imperantes, 
algunas locales y otras procedentes del Viejo Continente. Los objetos revelan la persistencia de ciertas formas tradicionales prehispánicas en el arte colonial y republicano, al tiempo que constituyen elementos identitarios. Por su parte, Carmen Heredia Moreno aborda un tema no menos interesante y complementario del tratado por Wuffarden: la platería virreinal peruana existente en España. Desde una época temprana de la colonización europea de los Andes, objetos muy diversos de plata cruzaron el Atlántico con destino a España. Mezclados con otras mercaderías, fuentes, platos, lámparas, custodias, candelabros y un sinnúmero de piezas finamente trabajadas se destinaron a palacios, iglesias, conventos. Sus comitentes fueron igual de diversos -arzobispos, obispos, virreyes, oidores, comerciantes, clérigos-, quienes mediante estos envíos buscaban engalanar la iglesia de su localidad natal, enaltecer el culto de alguna imagen de su devoción, regalar a algún allegado o halagar a algún poderoso. Los envíos de objetos de plata se mantuvieron hasta inicios del siglo XIX. Pero, en mi opinión, hubo coyunturas en que estas remesas fueron mayores, como por ejemplo cada vez que zarpaba la flota de la mar del sur o con ocasión de algún requerimiento especial de la Corona. Esto último se produjo, por ejemplo, luego de la expulsión de los jesuitas, en 1767, cuando por orden de la Corona, se dispuso que numerosos ornamentos litúrgicos que habían pertenecido a las iglesias y los colegios de la Compañía de Jesús fueran embalados para su envío a España. Hoy sabemos que una parte de dichos ornamentos quedó en el virreinato peruano para ser distribuidos en las iglesias, pero de aquellos que se enviarona la península no se sabe nada. Cierra esta primera parte, el breve y original ensayo de Emily Floyd acerca de los plateros que incursionaron en el arte del grabado. Maestros en el dominio del buril, algunos plateros grabaron planchas de metal que sirvieron para producir estampas destinadas a ilustrar impresos salidos de las imprentas limeñas.

3 La segunda parte de este libro está compuesta por un portafolio de 230 ilustraciones, en su mayoría de objetos de plata de los períodos colonial y republicano. Las ilustraciones han sido agrupadas en nueve apartados: La conquista frente al pasado indígena, Los inicios de una tradición, Barroco local y esplendor eclesiástico, El culto eucarístico, Devociones locales en la ruta de la plata, La irrupción del neoclasicismo, Plata y vida cotidiana, El adorno personal y El primer siglo republicano. La tercera parte del libro está compuesta por un documentado índice de plateros, a cargo de Luis Eduardo Wuffarden y Pablo Cruz, y la bibliografía consultada por los autores y editores del libro

Este merece un comentario especial. No se trata de cualquier texto, sino de uno que propone nuevas perspectivas de estudio e interrogantes en torno al arte de la orfebrería en un periodo de larga duración. Una tiene que ver con el universo social de los plateros, en particular con sus formas de aprendizaje. Aun cuando está documentada la circulación en el virreinato peruano de la obra de Juan de Arfe y Villafañe titulada Quilatador de la plata, oro y piedras -en el que, en entre otras cosas, se instruía cómo hacer aleaciones de plata y oro, así como avaluar los metales antes mencionados y las piedras preciosas-, el aprendizaje de los plateros, como el de los impresores y otros artesanos, se llevaba a cabo en los talleres. Se trataba de un aprendizaje práctico y poco teórico. Los registros notariales abundan de asientos de aprendices, muchos de ellos jóvenes, deseosos de hacerse de un lugar en tan prestigioso oficio. Para muestra, un ejemplo. El 15 de julio de 1659, Hernando de Ocampo, residente en la ciudad del Cuzco, se asentó con Francisco López de la Vega «maestro platero», en 
esa misma ciudad, por dos años «para serbirle y trabajar con el susodicho por oficial en el dicho su oficio de platería en todo lo que mandare por cuyo trabajo a de pagar dos reales cada día, casa y de comer» (Archivo Regional del Cuzco. Registro del escribano Juan Flores Bastidas, años 1657-1659, f. 270r,v.). Como era usual en la época, maestro y aprendiz no solo compartían los mismos espacios, sino que lo que más probable es que, como consecuencia de ello, las fronteras entre el aprendizaje y la servidumbre terminaran confundiéndose. ¿Quién fue Hernando de Ocampo? Por el momento no hay una respuesta a falta de mayor investigación. ¿Qué obras se le pueden atribuir? Tampoco lo sabemos.

Esto último nos lleva a tres cuestiones no menos interesantes y de no fácil resolución: los de la autoría, la procedencia y la datación de las piezas de plata. Como bien señala Carmen Heredia, no obstante lo mucho que se ha avanzado en el conocimiento de la platería virreinal, la identificación de las piezas se dificulta por la reiterada falta de marcas. Las disposiciones del Cabildo de Lima y de otras autoridades coloniales sobre la obligación de marcar la plata labrada fueron sistemáticamente desobedecidas. La pregunta es por qué la evasión de la norma. En cuanto a la autoría, procedencia y datación, las marcas y la documentación pueden arrojar alguna luz al respecto, pero no toda la que quisiéramos. De allí la necesidad, como lo ha planteado Wuffarden, del análisis estilístico de las piezas.

Más aún, resulta encomiable, por no decir heroico, el esfuerzo de Wuffarden y Kusunoki por ofrecer una panorama de la evolución de la platería colonial y republicana, cuando para todos es conocido que son muchas las piezas desaparecidas y que su único rastro es documental. La platería colonial ha pasado por múltiples vicisitudes: robos, fundiciones, destrucción deliberada... La historia de su sustracción es antigua y se puede estudiar, entre muchas otras fuentes, a partir de las cartas de censura que conserva el Archivo Arzobispal de Lima. Ayer, como hoy, las iglesias, los conventos y los domicilios particulares han sido objetos de hurto. Ante la falta de un sistema policial en los siglos coloniales, los agraviados acudían al Tribunal eclesiástico, el cual emitía cartas de censura en las que, bajo pena de excomunión, se compelía a los amigos de lo ajeno a devolver lo ilícitamente apropiado.

7 La preservación del patrimonio artístico legado de nuestros antepasados es una cuestión de siempre permanente actualidad. La preservación de dicho patrimonio debería ser no solo responsabilidad de las autoridades, sino también de todos nosotros, porque constituye parte esencial de nuestra memoria histórica, de nuestro devenir como nación. Por ello, son más que meritorios los esfuerzos del MALI y del Banco de Crédito por publicar libros como este, porque promueven el estudio y alientan la conservación del patrimonio artístico peruano. Este nuevo libro se suma a muchos otros de gran valor sobre el arte del Perú. Al repasar sus páginas no podemos menos que sentirnos orgullosos de nuestro pasado y de nuestras tradiciones. 


\section{AUTORES}

PEDRO M. GUIBOVICH PÉREZ

Pontificia Universidad Católica del Perú 